TITLE:

\title{
Preparation of Biodegradable Gelatin Nanospheres with a Narrow Size Distribution for Carrier of Cellular Internalization of Plasmid DNA.
}

\section{$\operatorname{AUTHOR}(\mathrm{S}):$}

Doi, Norio; Jo, Jun-Ichiro; Tabata, Yasuhiko

\section{CITATION:}

Doi, Norio ... [et al]. Preparation of Biodegradable Gelatin Nanospheres with a Narrow Size Distribution for Carrier of Cellular Internalization of Plasmid DNA.. Journal of biomaterials science. Polymer edition 2011, 23(8): 991-1004

ISSUE DATE:

2011-04-04

URL:

http://hdl.handle.net/2433/154869

\section{RIGHT:}

Copyright 2012 Brill.; この論文は出版社版でありません。引用の際には 出版社版をご確認ご利用ください。; This is not the published version. Please cite only the published version. 


\section{Preparation of biodegradable gelatin nanospheres with a narrow size distribution for carrier of cellular internalization of plasmid DNA}

Norio Doi, Jun-ichiro Jo, and Yasuhiko Tabata

Department of Biomaterials, Institute for Frontier Medical Sciences, Kyoto University, 53 Kawara-cho Shogoin, Sakyo-ku Kyoto 606-8507, Japan

Running Title: Gelatin spheres for intracellular DNA release

Correspondence to Dr. Yasuhiko Tabata, Department of Biomaterials, Field of Tissue Engineering, Institute for Frontier Medical Sciences, Kyoto University, 53 Kawara-cho Shogoin, Sakyo-ku Kyoto 606-8507, Japan.

TEL $\quad+81-75-751-4121$

FAX +81-75-751-4646

E-mail yasuhiko@frontier.kyoto-u.ac.jp 


\section{Abstract}

The objective of this study is to design the biodegradable nanospheres of cationized gelatin as a carrier of cellular internalization of plasmid DNA. Ethylenediamine was chemically introduced into the carboxyl groups of gelatin to obtain cationized gelatin. The gelatin solution was filtered through a glass membrane under a high pressure and dropped into 2-butanol, acetone or the mixture to form nanospheres of cationized gelatin. The microspheres of cationized gelatin were prepared by the conventional water-in-oil emulsion method. The resulting nano- and microspheres of cationized gelatin were dehydrothermally treated at $160{ }^{\circ} \mathrm{C}$ for different time periods to allow them to crosslink chemically. The size of nanospheres prepared by the filtration method was changed by the type of solvents used to be $1.86,0.83$ or $0.24 \mu \mathrm{m}$. The in vitro degradation of spheres became faster as the time period of dehydrothermal treatment was shorter. The degradation time of spheres in $\mathrm{HCl}$ solution linearly increased with an increase in the crosslinking time, irrespective of the sphere size. However, in the collagenase solution, when compared at the similar crosslinking density, the smaller spheres were degraded more slowly than the larger ones. The plasmid DNA incorporated in the nanospheres was released from the nanospheres with their degradation. The nanospheres incorporating plasmid DNA were internalized into cells, and intracellularly degraded with time to release plasmid DNA. The time period of 
plasmid DNA release prolonged by increasing that of nanospheres degradation.

Keywords: Cationized gelatin microspheres and nanospheres / Biodegradation / Cellular internalization / Intracellular release 


\section{Introduction}

Intracellular delivery of plasmid DNA has been tried for gene transfection

either by viral or non-viral carriers system. Viral carriers of adenoviruses, retroviruses, adeno-associated viruses, and lentivirus possess the inherently high efficiency of gene transfection and have been extensively used for biological researches [1-7]. However, there are some problems to be resolved for the clinical trials, such as the immunological and/or toxic responses toward the carriers themselves. The genetic modulations of viral carriers have been attempted to reduce their biological responses [8]. As other different approaches, non-viral carriers have been explored to demonstrate several advantages over the viral carriers. For the non-viral transfection system, naked plasmid DNA alone or the complexes with cationic liposomes, cationic lipids, and cationic polymers have been utilized [9-12]. However, the level of gene transfection is low compared with that of viral carriers, and the time period is shorter. To maintain the gene expression for a long time period, repeated transfection has been performed, but the frequent use of non-viral carriers is practically not acceptable and sometimes may cause toxicity. As one technology to resolve the issues, drug delivery system (DDS) of plasmid DNA is effective. Various sustained release of plasmid DNA with polymeric implants and hydrogels have been being investigated [13-19].

Gelatin has been extensively used for industrial, pharmaceutical, and medical 
applications and the bio-safety has been proven through its long clinical use as biomaterial and drug ingredients [20]. Other advantages of gelatin include the availability of samples with various physicochemical natures and the simple chemical modification. Hydrogels of gelatin were effective in the sustained release of proteins and low-molecular-weight drug [21-27]. Cationized gelatin can readily be prepared by introducing amine residues to the carboxyl groups of gelatin. The biodegradable microspheres of cationized gelatin functioned as a good carrier for plasmid DNA release $[28,29]$. The plasmid DNA was released from the gelatin microspheres as a result of their degradation [21].

In this study, the biodegradable nanospheres with a narrow size distribution were prepared from cationized gelatin to allow plasmid DNA to internalize into cells for the intracellular sustained release. A filtration method was used to prepare nanosopheres and the degradability of nanospheres was charged by altering their crosslinking condition in preparation. The nanospheres degradation was examine in the $\mathrm{HCl}$ solution or collagenase solution. We examined the cellular internalization of cationized gelatin nanospheres with different crosslinking densities and the subsequent sustained release of plamid DNA intracellularly. 


\section{Materials and Methods}

\section{Preparation of cationized gelatin}

The carboxyl groups of gelatin, with an isoelectric point of 9.0 and the weight-avaraged molecular weight of 99,000, prepared by an acidic process of pig skin (Nitta Gelatin Inc., Osaka, Japan), were converted by chemically introducing amino groups for cationization of gelatin [21]. Ethylenediamine (Wako Pure Chemical Industries, Ltd., Osaka, Japan) was added at a molar ratio of 50 to the carboxyl groups of gelatin into $250 \mathrm{ml}$ of $100 \mathrm{mM}$ phosphate-buffered solution ( $\mathrm{pH} 5.0$ ) containing $5.0 \mathrm{~g}$ of gelatin. Immediately after that, the solution $\mathrm{pH}$ was adjusted to 5.0 by adding $11 \mathrm{M}$ $\mathrm{HCl}$ aqueous solution. Further, 1-ethyl-3-(3-dimethylaminopropyl) carbodiimide hydrochloride salt (Nacalai Tesque. Inc., Kyoto, Japan) was added at a molar ratio of 3 to the carboxyl groups of gelatin. The reaction mixture was agitated at $37{ }^{\circ} \mathrm{C}$ for $18 \mathrm{hr}$ and then dialyzed against double-distilled water (DDW) for $48 \mathrm{hr}$ at room temperature. The dialyzed solution was freeze-dried to obtain a cationized gelatin. When determined by the conventional 2,4,6-trinitrobenzene sulfonic acid (TNBS, Wako Pure Chemical Industries, Ltd., Osaka, Japan) method [30], the percentage of amino groups introduced into gelatin was 45 mole $\%$ per the carboxyl groups of gelatin. 


\section{Preparation of cationized gelatin microspheres and nanospheres}

Spheres with different sizes were prepared from cationized gelatin by two methods. For the first method, aqueous solution of $10 \mathrm{wt} \%$ cationized gelatin $(10 \mathrm{ml})$ was preheated at $40^{\circ} \mathrm{C}$ and then added dropwise into $600 \mathrm{ml}$ of olive oil preheated at $40^{\circ} \mathrm{C}$, while an impeller stirring at $400 \mathrm{rpm}$ was used for $10 \mathrm{~min}$ to yield a water-in-oil emulsion. The emulsion temperature was decreased to $4{ }^{\circ} \mathrm{C}$ for the natural gelation of gelatin solution. The resulting microspheres were washed three times with cold acetone, collected by centrifugation $\left(5,000 \mathrm{rpm}, 4^{\circ} \mathrm{C}, 5 \mathrm{~min}\right)$, fractionated in size by sieves with an aperture of $32 \mu \mathrm{m}$ and air-dried at room temperature. The non-cross linked and dried gelatin microspheres $(100 \mathrm{mg})$ were placed in a vacuum oven (Sato vacuum machinery industrial Co., LTD., Tokyo, Japan) at $160^{\circ} \mathrm{C}$ for different time periods to allow them to dehydrothermally crosslink.

The second preparation was done according to the filtration method reported previously [31]. Briefly, aqueous solution of $2.5 \mathrm{wt} \%$ cationized gelatin $(10 \mathrm{ml})$ was preheated at $40{ }^{\circ} \mathrm{C}$ and applied to an apparatus of emulsion preparation (External pressure type micro kit, SPG Technology Co. Ltd., Miyazaki, Japan). The solution was filtered under a pressure of $350 \mathrm{kPa}$ through a grass membrane with homogenous pores of 0.2 or $0.6 \mu \mathrm{m}$ (SPG membrane, SPG Technology Co. Ltd., Miyazaki, Japan) and 
dispersed in 2-butanol, acetone, and the mixture to prepare a water-in-oil emulsion. The resulting emulsion was air-dried at room temperature to obtain non-crosslinked cationized gelatin nanospheres. The non-crosslinked and dried gelatin microspheres $(100 \mathrm{mg})$ were placed in vacuum oven at $160{ }^{\circ} \mathrm{C}$ for different time periods to allow them to dehydrothermally crosslink. The shape of crosslinked gelatin microspheres was observed by a transmission electron microscope or a light microscope.

Measurement of water content and crosslinking density of cationized gelatin microspheres and nanospheres

Cationized gelatin microspheres or nanospheres dehydrothermally crosslinked (2 mg) were fully swollen in DDW for $3 \mathrm{hr}$ at $37^{\circ} \mathrm{C}$ to reach an equilibrium state. Then, the picture of swollen spheres and dried ones before swelling were taken under microscope (Olympus Corp., Tokyo, Japan). The diameter of 400 cationized gelatin microspheres and nanospheres in the swollen and dried states was measured to calculate the respective volumes, $\mathrm{V}_{\mathrm{s}}$ and $\mathrm{V}_{\mathrm{d}}$. The water content was calculated by following equation; Water content $=\mathrm{V}_{\mathrm{s}}-\mathrm{V}_{\mathrm{d}} / \mathrm{V}_{\mathrm{s}} \times 100(\%)$. The crosslinking density of cationized gelatin microspheres or nanospheres was calculated by the following equation (Flory-Huggins equation); $\ln \left(1-\Phi_{2}\right)+\Phi_{2}+\chi \Phi_{2}{ }^{2}+v_{1}\left(v_{\mathrm{e}} / \mathrm{V}_{0}\right)\left(\Phi_{2}{ }^{1 / 3}-\Phi_{2} / 2\right)=0$, where $\Phi_{2}$ is the 
volume fraction of polymer at equilibrium (i.e., in the fully swollen sample), $\chi$ is the Flory-Huggins interaction parameter, $v_{1}$ is the molar volume of water, $v_{\mathrm{e}}$ is the effective number of chains in the network, and $\mathrm{V}_{0}$ is the volume of unswollen (i.e., dry) polymer network. The $v_{\mathrm{e}} / \mathrm{V}_{0}$ is defined as the effective network chain concentration or effective chain density (in the unit of $\mathrm{mol} / \mathrm{cm}^{3}$ ). From the volume of spheres, the crosslinking density per sphere was calculated.

Evaluation of in vitro degradation of cationized gelatin microspheres and

\section{nanospheres}

Cationized gelatin microspheres or nanospheres dehydrothermally crosslinked $\left(10 \mathrm{mg}\right.$ ) were fully swollen in $750 \mu \mathrm{l}$ of DDW for $12 \mathrm{hr}$ at $25{ }^{\circ} \mathrm{C}$. Then, $750 \mu \mathrm{l}$ of $2 \mathrm{~N}$ $\mathrm{HCl}$ aqueous solution was added and incubated at $25{ }^{\circ} \mathrm{C}$ for various time periods. The solution was centrifuged at $5000 \mathrm{rpm}, 25^{\circ} \mathrm{C}$ for $5 \mathrm{~min}$ while $200 \mu \mathrm{l}$ of supernatant was collected. After that, $200 \mu \mathrm{l}$ of fresh $1 \mathrm{~N} \mathrm{HCl}$ aqueous solution was added and continued to incubate at $25{ }^{\circ} \mathrm{C}$. To measure the amount of cationized gelatin degraded by $\mathrm{HCl}$, the adsorption of supernatant collected at $260 \mathrm{~nm}$ was measured by an ultraviolet-visible (UV) spectroscopy (DU® 800 Spectrophotometer, Beckman Coulter, Inc., Fullerton, CA). Similar degradation was performed in $600 \mathrm{ng} / \mathrm{ml}$ of aqueous 
solution of collagenase 1A (Sigma-aldrich, Inc., St. Louis, MO). These samples were used for each experiment independently unless mentioned otherwise.

\section{In vitro release of plasmid DNA from cationized gelatin microspheres and}

\section{nanospheres and in vitro degradation of spheres}

The plasmid DNA of firefly luciferase (GL3) was radioiodinated according to a chloramine T method [32]. Briefly, $200 \mu \mathrm{l}$ of $200 \mu \mathrm{g} / \mathrm{ml}$ plasmid DNA solution was added into $100 \mu \mathrm{l}$ of $0.5 \mathrm{M}$ potassium phosphate-buffered (KPB) solution (pH7.5) containing $0.5 \mathrm{M} \mathrm{NaCl}$. Then, $5 \mu \mathrm{l}$ of $\mathrm{Na}^{125} \mathrm{I}(740 \mathrm{MBq} / \mathrm{ml}$ in $0.1 \mathrm{M} \mathrm{NaOH}$ aqueous solution, NEN Research Products) solution and $100 \mu$ of 0.05 M KPB solution (pH7.2) containing $0.02 \mathrm{mg}$ of chloramine $\mathrm{T}$ and $0.5 \mathrm{M} \mathrm{NaCl}$ were added to the plasmid DNA solution. After agitation at room temperature for $2 \mathrm{~min}, 100 \mu \mathrm{l}$ of DDW containing 0.4 mg of sodium pyrosulfite (SMS, Nacalai Tesque Inc., Kyoto, Japan) was added to stop the radioiodination. The resulting mixture was passed through a PD-10 column (GE healthcare UK Ltd., Buckinghamshire, UK) to remove uncoupled, free ${ }^{125}$ I molecules to obtain an aqueous solution of ${ }^{125}$ I-labeled plasmid DNA. The absorbance ratio at wavelengths of $260 \mathrm{~nm}$ was measured to determine the concentration of ${ }^{125}$ I-labeled plasmid DNA. The radioiodinated plasmid DNA solution $(100 \mu \mathrm{l})$ was dropped onto 10 
mg of cationized gelatin microspheres and nanospheres dehydrothermally crosslinked, followed by leaving at $4{ }^{\circ} \mathrm{C}$ for $12 \mathrm{hr}$ to prepare the microspheres incorporating ${ }^{125}$ I-labeled plasmid DNA. Then, the microspheres was washed with $10 \mathrm{mM}$ phosphate-buffered saline solution (PBS) by centrifugation, and incubated in $1.5 \mathrm{ml}$ of $1 \mathrm{M} \mathrm{HCl}$ at $25{ }^{\circ} \mathrm{C}$ for different time periods. The radioactivity of microspheres remaining was measured to evaluate the time profile of plasmid DNA release from microspheres. The in vitro degradation of gelatin nanospheres incorporating ${ }^{125}$ I-labeled plasmid DNA was evaluated similarly. Following the incubation of nanospheres in the $\mathrm{HCl}$ solution, the amount of gelatin solubilized in PBS was determined by the UV spectroscopic absorption in the same procedure as described above at different time intervals.

\section{Preparation of mesenchymal stem cells}

Mesenchymal stem cells (MSC) were prepared from the bone marrow of 3-week-old, male Wister rats (Shimizu Laboratory Supplies Co., Ltd., Kyoto, Japan) according to the conventional procedure reported [33]. Briefly, both the ends of rat femurs were cut away from the epiphysis, and the bone marrow was flushed out using a syringe (21 gauge needle) with $1 \mathrm{ml}$ of PBS. The cell suspension was centrifuged and 
resuspended in $4 \mathrm{ml}$ of alpha minimum essential medium ( $\alpha \mathrm{MEM})$ supplemented with $15 \mathrm{vol} \%$ fetal calf serum (FCS), penicillin $(50 \mathrm{U} / \mathrm{ml})$, and streptomycin $(50 \mathrm{U} / \mathrm{ml})$ (standard medium) and placed into two $25 \mathrm{~cm}^{2}$ flasks (Iwaki Glass Co., Funabashi, Chiba, Japan), followed by culturing at $37{ }^{\circ} \mathrm{C}$ in a $95 \%$ air-5\% carbon dioxide atmosphere. The medium was exchanged 3 days after the culture and thereafter every 3 days. When the cells became sub-confluent, 7 to 10 days culture later, they were detached by treatment with PBS containing $0.25 \mathrm{wt} \%$ trypsin and $0.02 \mathrm{wt} \%$ ethylenediaminetetraacetic acid for $5 \mathrm{~min}$ at $37{ }^{\circ} \mathrm{C}$, and subcultured at a density of $2 \times 10^{4}$ cells $/ \mathrm{cm}^{2}$. When proliferated in a sub-confluence condition, the cells were used for the following experiments.

Evaluation of cellular internalization of cationized gelatin microspheres and nanospheres

Cationized gelatin microspheres and nanospheres were labeled by fluorescein isothiocyanate (FITC) according to the procedure reported [32], while the Cy5 labeling of plasmid DNA was performed by using Label IT ${ }^{\circledR}$ Cy5 Labeling Kit (Mirus ${ }^{\circledR}$, Madison, WI) according to the manufacturers' instructions. The Cy5-labeled plasmid DNA was incorporated into each sphere by the same procedure mentioned above. The 
transfection experiments for MSC were performed by the conventional and reverse transfection methods [34]. For the conventional transfection method, MSC were seeded on each well of 6 well multi-dish culture plate (Corning Inc., Corning, NY) at a density of $5 \times 10^{4} \mathrm{cells} /$ well and cultured in $1 \mathrm{ml}$ of $\alpha-$ MEM medium with 15 vol\% FCS for 24 hr. Then, the medium was exchanged to FCS-free $\alpha$-MEM medium, and the microspheres and nanospheres incorporating plasmid DNA were added to each well. The transfection culture was performed for $6 \mathrm{hr}$, and thereafter the cells were incubated in $\alpha$-MEM with FCS further for 1, 3, and 7 days. For the reverse transfection method, the anionized derivatives of gelatin was prepared and the anionized gelatin solution (1 $\mathrm{mg} / \mathrm{ml}$ ) and different amounts of Pronectin ${ }^{\circledR}$ (Sanyo Chemical Industries Ltd., Kyoto, Japan) were placed into each well of a 6 well culture plate and left at $37^{\circ} \mathrm{C}$ for $1 \mathrm{hr}$ for their coating. After PBS washing, microspheres or nanospheres incorporating plasmid DNA were added into each well, and the well was washed with PBS 30 min later. Next, MSC $\left(5 \times 10^{4}\right.$ cells/well) were seeded into the well treated, followed by cell culture in the $\alpha$-MEM medium with 15 vol\% FCS for 1,3 , and 7 days. At different time intervals after the transfection culture for appropriate intervals with the microspheres or nanospheres incorporating plasmid DNA, cells were washed and fixed with $0.25 \mathrm{wt} \%$ glutaraldehyde solution in PBS. Imaging data of cells were collected on an Olympus 
Fluoview FV300 confocal laser scanning microscope (Olympus Corp., Tokyo, Japan) and processed with Adobe Photoshop 6.0 software (Adobe Systems Inc., San Jose, CA). On the other hand, after the transfection culture with the microspheres or nanospheres incorporating plasmid DNA, the cells were treated in cold acetate-buffered solution containing $0.3 \mathrm{vol} \%$ acetic acid, $0.085 \mathrm{M} \mathrm{NaCl}$, and $5.0 \mathrm{mM} \mathrm{KCl}$ for $1 \mathrm{~min}$, then the cells were washed with cold PBS to remove the microspheres or nanospheres bound onto the surface of cells. The cells were collected by the trypsinization and ten thousand cells were measured by the fluorescence activated cell sorter (FACSCalibur, Becton, Dickinson, and Company, Franklin Lakes, NJ) with Cell Quest Pro Software. The percentage of FITC or Cy5 -positive cells was calculated by setting the background population as 98\% negative when analyzing control cells [35]. Experiments were performed independently 3 times for each group.

\section{Statistical analysis}

Data were expressed as means \pm standard deviations. Data were analyzed using Tukey-Kramer paired comparison test, while the significance was accepted at $p<0.05$.

\section{Results}

Preparation of cationized gelatin microspheres and nanospheres 
Table 1 shows the preparation conditions and characterization of cationized gelatin microspheres and nanospheres. Cationized gelatin spheres with various sizes were prepared by changing the emulsification method and solvent used. Cationized gelatin nanospheres prepared by the filtration method had nano-order ranges of size with a narrow size distribution. The nanospheres size was changed by changing the solvent type even for the same glass membrane. The microspheres with a larger distribution in size were prepared by the stirring method. The sphere size did not change by the procedure of plasmid DNA incorporation (data not shown).

Figure 1 shows the microscopic pictures of cationized gelatin microspheres and nanospheres. Every cationized gelatin microsphere had a spherical shape with smooth surface.

Figure 2 shows the water content of cationized gelatin microspheres and nanospheres prepared. The size of microspheres with $0.24 \mu \mathrm{m}$ in diameter was too small to measure their size in the swollen state. As the time period of dehydrothermal treatment became longer, the water content of spheres became lower. No dependence of spheres size on their water content was observed.

\section{Degradation profiles of cationized gelatin microspheres and nanospheres}


Figure 3 shows the degradation profiles of microspheres and nanospheres with different times of dehydrothermal treatment. The degradation of microspheres and nanospheres became slower with an increase in the treatment time.

Figure 4 shows the degradation profiles of microspheres and nanospheres with different sizes. The time profile of nanospheres degradation was similar for every size. On the other hand, the microspheres were degraded more slowly.

Figure 5 shows the relationship between the $\mathrm{HCl}$ degradation of microspheres and nanospheres and their crosslinking density. Irrespective of the spheres type, their degradation time was linearly correlated with their crosslinking density.

Figure 6 shows the relationship between the spheres degradtion in collagenase solution and their crosslinking density. In the collagenase degradation, the linear dependence was not observed. When compared at the same crosslinking density, the smaller nanospheres were degraded slowly compared with larger spheres. Crosslinking density, defined as the crosslinking number per gelatin molecule, of the smaller spheres was higher than that of large spheres.

Figure 7 shows the relationship between the collagenase degradation of microspheres and nanospheres and their crosslinking number per gelatin molecule. A good correlation was observed between the two values, irrespective of the sphere size. 


\section{Release profiles of plasmid DNA from cationized gelatin microspheres and nanospheres}

Figure 8 shows the time profiles of cationized gelatin nanospheres degradation and plasmid DNA release. Although the initial burst of plasmid DNA release was large compared with that of nanospheres degradation, their decrement pattern was similar. The nanospheres were degraded completely on day 24 when the plasmid DNA was finished to be released. The similar time profiles were observed for every type of spheres (data not shown).

Cellular internalization of cationized gelatin nanospheres and thier intracelluar behavior

Figure 9 shows the cellular internalization of FITC-labeled cationized gelatin nanospheres. The percentage of nanospheres internalized into cells by the reverse transfection method was significantly higher than that of conventional method.

Figure 10 shows the cellular internalization of FITC-labeled cationized gelatin microspheres and nanospheres. Nanospheres with sizes of 0.22 and $0.83 \mu \mathrm{m}$ were internalized into cells whereas those with the sizes of 1.86 and $7.8 \mu \mathrm{m}$ were not. The 
percentage of smaller nanospheres internalized was significantly higher than that of larger ones.

Figure 11 shows the time profiles of the intracellular remaining of nanospheres incorporating plasmid DNA and the plasmid DNA incorporated. The nanospheres used were crosslinked by dehydrothermal treatment for 48 and $120 \mathrm{hr}$. The nanospheres treated for $120 \mathrm{hr}$ were retained in the cells for a long time period compared with those for $48 \mathrm{hr}$. The plasmid DNA remained in the cells for a long time period for nanospheres prepared by $120 \mathrm{hr}$ dehydrothermal treatment.

\section{Discussion}

The present study demonstrates that the nanospheres of cationized gelatin were a good carrier to allow plasmid DNA to internalize into cells and subsequently release intracellularly. The cellular internalization of nanospheres was greatly influenced by their size and the subsequent intracellular release of plasmid DNA was governed by the degradability of nanospheres. The nano-orders spheres could be prepared effectively by the filtration method and their distribution in size was narrow compared with those prepared by the conventional stirring method (Table 1). The plasmid DNA was released from the nanospheres as a result of their degradation as reported previously [21]. The prolonged time period of plasmid DNA release in the cells was observed for the 
nanospheres with slower degradability which can be change by the time period of dehydrothermal treatment (Figure 11).

The filtration method was effective in preparing nanospheres with a narrow size distribution. It is possible that the narrow size distribution of nanospheres resulted from the permeation of gelatin solution through the membrane with a homogenous pore size. This procedure will generate effectively the same volume of gelatin solution. When the gelatin solution was poured into the non-solvent of gelatin, gelatin molecules were precipitated to form spheres. Since the concentration and volume of gelatin solution poured are similar, the size of gelatin precipitates would become similar. The size depended on the type of solvents used (Table 1). In acetone, the size of nanospheres was very small. This is because acetone has a strong dehydration property compared with 2-butanol. It is likely that the solution of cationized gelatin was strongly dehydrated in acetone, resulting in formation of small-size nanospheres due to the strong precipitation. The degradation profiles of nanospheres depended on the time period of dehydrothermal treatment in preparation. The dehydrothermal treatment enables gelatin molecule to intramolecularly crosslink between the carboxyl and hydroxyl or amino groups by excluding water from molecules. Longer treatment increased the crosslinking extent of gelatin molecules. It is apparent that the increase in 
the time period of dehydrothermal crosslinking resulted in the higher crosslinking density of microspheres and nanospheres prepared (Figures 4 and 5). It is highly conceivable that higher crosslinking density of spheres brought about their slower degradation [36]. A good correlation of spheres degradation and their crosslinking density was observed in the $\mathrm{HCl}$ test (Figure 5). However, the correlation was not in the degradation test of collagenase solution (Figure 6). This can be explained in terms of the crosslinking homogeneity and the molecular size of $\mathrm{HCl}$ and collagenase molecules. Irrespective of the spheres size, as the crosslinking was homogenous in the spheres, it is likely that the degradation rate of spheres depends on their crosslinking density. The higher the crosslinking density, the longer the time period of spheres degradation. However, the molecular size of collagenase is much larger than that of $\mathrm{HCl}$. Consequently, the degradation by collagenase will be greatly influenced by the crosslinking density of microspheres and nanospheres. When the crosslinking density per one sphere is same, the molecular density per one microsphere will be lower for larger spheres than that of larger ones. As a result, the small spheres would be degraded slowly (Figure 6).

Small nanospheres were internalized into cells, in remarked contrast to larger ones. Since MSC are non-phagocytic cells, it is known that the cells cannot take up 
larger particles $[37,38]$. In this study, the size dependence of spheres internalization was observed (Figure 10). The nanospheres prepared for longer treatment time in dehydrothermal crosslinking were slowly degraded even inside the cells compared with those for the shorter treatment time (Figure 11). The longer retention of plasmid DNA in the cells was detected for the nanospheres slowly degraded (Figure 11). This strongly suggests that the nanospheres were degraded intracellularly with time, resulting in the release of plasmid DNA incorporated. It is concluded that the filtration method was effective in preparing biodegradable gelatin nanospheres with a narrow size distribution for the intracellular plasmid DNA release. 


\section{References}

1. Y. Gafni, G. Turgeman, M. Liebergal, G. Pelled, Z. Gazit, and D. Gazit, Gene Ther 11, 417(2004)

2. S. C. Chang, H. L. Chuang, Y. R. Chen, J. K. Chen, H. Y. Chung, Y. L. Lu, H. Y. Lin, C. L. Tai, and J. Lou, Gene Ther 10, 2013(2003)

3. K. C. Cho, S. H. Kim, J. H. Jeong, and T. G. Park, Macromol Biosci 5, $512(2005)$

4. G. Turgeman, D. D. Pittman, R. Muller, B. G. Kurkalli, S. Zhou, G. Pelled, A. Peyser, Y. Zilberman, I. K. Moutsatsos, and D. Gazit, J Gene Med 3, 240(2001)

5. A. A. Mangi, N. Noiseux, D. Kong, H. He, M. Rezvani, J. S. Ingwall, and V. J. Dzau, Nat Med 9, 1195(2003)

6. H. Sato, N. Kuwashima, T. Sakaida, M. Hatano, J. E. Dusak, W. K. Fellows-Mayle, G. D. Papworth, S. C. Watkins, A. Gambotto, I. F. Pollack, and H. Okada, Cancer Gene Ther 12, 757(2005)

7. M. Studeny, F. C. Marini, J. L. Dembinski, C. Zompetta, M. Cabreira-Hansen, B. N. Bekele, R. E. Champlin, and M. Andreeff, J Natl Cancer Inst 96, 1593(2004)

8. H. Mizuguchi, M. A. Kay, and T. Hayakawa, Adv Drug Deliv Rev 52, 165(2001)

9. S. C. De Smedt, J. Demeester, and W. E. Hennink, Pharm Res 17, 113(2000)

10. K. Ewert, N. L. Slack, A. Ahmad, H. M. Evans, A. J. Lin, C. E. Samuel, and C. 
R. Safinya, Curr Med Chem 11, 133(2004)

11. M. C. Pedroso de Lima, S. Neves, A. Filipe, N. Duzgunes, and S. Simoes, Curr Med Chem 10, 1221(2003)

12. A. Hirko, F. Tang, and J. A. Hughes, Curr Med Chem 10, 1185(2003)

13. D. Luo, K. Woodrow-Mumford, N. Belcheva, and W. M. Saltzman, Pharm Res 16, 1300(1999)

14. W. L. Murphy and D. J. Mooney, J Periodontal Res 34, 413(1999)

15. T. Ochiya, Y. Takahama, S. Nagahara, Y. Sumita, A. Hisada, H. Itoh, Y. Nagai, and M. Terada, Nat Med 5, 707(1999)

16. L. D. Shea, E. Smiley, J. Bonadio, and D. J. Mooney, Nat Biotechnol 17, $551(1999)$

17. D. Wang, D. R. Robinson, G. S. Kwon, and J. Samuel, J Control Release 57, 9(1999)

18. Z. Megeed, J. Cappello, and H. Ghandehari, Pharm Res 19, 954(2002)

19. J. H. Jang and L. D. Shea, J Control Release 86, 157(2003)

20. R. Schrieber and H. Gareis, Gelatine Handbook: Theory and Industrial Practice. 2007: Wiley. 347.

21. Y. Fukunaka, K. Iwanaga, K. Morimoto, M. Kakemi, and Y. Tabata, J Control 
Release 80, 333(2002)

22. M. Konishi, Y. Tabata, M. Kariya, A. Suzuki, M. Mandai, K. Nanbu, K. Takakura, and S. Fujii, J Control Release 92, 301(2003)

23. G. Matsumoto, T. Kushibiki, Y. Kinoshita, U. Lee, Y. Omi, E. Kubota, and Y. Tabata, Cancer Sci 97, 313(2006)

24. M. Nakamura, J. Jo, Y. Tabata, and O. Ishikawa, Am J Pathol 172, 650(2008)

25. Y. Tabata, S. Hijikata, M. Muniruzzaman, and Y. Ikada, J Biomater Sci Polym Ed 10, 79(1999)

26. M. Yamamoto, Y. Ikada, and Y. Tabata, J Biomater Sci Polym Ed 12, 77(2001)

27. M. Yamamoto, Y. Tabata, L. Hong, S. Miyamoto, N. Hashimoto, and Y. Ikada, J Control Release 64, 133(2000)

28. T. Kushibiki, R. Tomoshige, Y. Fukunaka, M. Kakemi, and Y. Tabata, J Control Release 90, 207(2003)

29. T. Kushibiki, K. Matsumoto, T. Nakamura, and Y. Tabata, Gene Ther 11, $1205(2004)$

30. S. L. Snyder and P. Z. Sobocinski, Anal Biochem 64, 284(1975)

31. T. Nakashima, M. Shimizu, and M. Kukizaki, Adv Drug Deliv Rev 45, 47(2000)

32. G. T. Hermanson, Bioconjugate Techniques. 1996: Academic Press. 
33. M. F. Pittenger, A. M. Mackay, S. C. Beck, R. K. Jaiswal, R. Douglas, J. D. Mosca, M. A. Moorman, D. W. Simonetti, S. Craig, and D. R. Marshak, Science 284, 143(1999)

34. A. Okazaki, J. Jo, and Y. Tabata, Tissue Eng 13, 245(2007)

35. F. Lampariello, Cytometry 15, 294(1994)

36. M. Ozeki and Y. Tabata, J Biomater Sci Polym Ed 16, 549(2005)

37. T. Tokatlian, C. T. Shrum, W. M. Kadoya, and T. Segura, Biomaterials 31, 8072

38. J. Jo, I. Aoki, and Y. Tabata, J Control Release 142, 465 


\section{Figure Legends}

Figure 1. Microscopic pictures of cationized gelatin microspheres and nanospheres with sizes of (A) 0.24, (B) 0.83, and (C) $7.80 \mu \mathrm{m}$.

Figure 2. Water content of cationized gelatin microspheres and nanospheres as a function of dehydrothermal crosslinking time period. The size of microspheres used is (०) $0.85,(\triangle) 1.86$ or $(\square) 7.8 \mu \mathrm{m}$.

Figure 3. In vitro degradation profiles of cationized gelatin nanospheres with the size of $0.85 \mu \mathrm{m}$ dehydrothermally crosslinked at $160{ }^{\circ} \mathrm{C}$ for $(\circ) 48,(\bullet) 72,(\Delta) 96$, and $(\boldsymbol{\Delta})$ $120 \mathrm{hr}$.

Figure 4. In vitro degradation profiles of gelatin microspheres and nanospheres dehydrothermally crosslinked at $160^{\circ} \mathrm{C}$ for $120 \mathrm{hr}$. The size of microspheres used is ( $\left.\mathrm{O}\right)$ $0.24,(\bullet) 0.85,(\triangle) 1.86$ or $(\mathbf{\Delta}) 7.8 \mu \mathrm{m}$.

Figure 5. Relationship between the time period of microspheres and nanospheres degradation and their crosslinking density per sphere. The microspheres were degraded 
in $1 \mathrm{~N} \mathrm{HCl}$ solution at $25^{\circ} \mathrm{C}$. The size of microspheres used is $(\bullet) 0.85,(\Delta) 1.86$ or $(\boldsymbol{\Delta})$ $7.8 \mu \mathrm{m}$.

Figure 6. Relationship between the time period of microspheres and nanospheres degradation and the crosslinking density per sphere. The microspheres and nanospheres were degraded in $600 \mathrm{ng} / \mathrm{ml}$ collagenase solution at $37^{\circ} \mathrm{C}$. The size of microspheres used is $(\bullet) 0.85,(\triangle) 1.86$ or $(\boldsymbol{\Delta}) 7.8 \mu \mathrm{m}$.

Figure 7. Relationship between the time period of microspheres and nanospheres degradation and the crosslinking number per gelatin molecule. The microspheres and nanospheres were degraded in $600 \mathrm{ng} / \mathrm{ml}$ collagenase solution at $37{ }^{\circ} \mathrm{C}$. The size of microspheres used is $(\bullet) 0.85,(\triangle 1.86$ or $(\mathbf{\Delta}) 7.8 \mu \mathrm{m}$.

Figure 8. The time profiles of radioactivity remaining of ${ }^{125}$ I-labeled plasmid DNA (०) and the degradation of cationized gelatin nanospheres $(\bullet)$. The microspheres with the size of $0.83 \mu \mathrm{m}$ dehydrothermally treated at $160{ }^{\circ} \mathrm{C}$ for $72 \mathrm{hr}$ were degraded in $1 \mathrm{~N} \mathrm{HCl}$ solution at $25^{\circ} \mathrm{C}$. 
Figure 9. Cellular internalization of FITC-labeled nanospheres with the size of $0.24 \mu \mathrm{m}$

$24 \mathrm{hr}$ after culture with MSC by the conventional and reverse transfection methods. *, p

$<0.05$; significant between the two groups.

Figure 10. Confocal laser microscopy images of cellular internalization of cationized gelatin nanospheres incorporating plasmid DNA $24 \mathrm{hr}$ after culture with MSC. Green: FITC-labeled cationized gelatin nanospheres. Red: Cy5-labeled plasmid DNA. The size of nanospheres used is (A) 0.24 and (B) $0.83 \mu \mathrm{m}$. (C) Percent internalized of FITC-labeled nanospheres with sizes of 0.24 and $0.83 \mu \mathrm{m} .{ }^{*}, \mathrm{p}<0.05$; significant between the two groups.

\section{Figure 11.}

Time profiles of cellular internalization of different FITC-labeled nanospheres incorporating Cy5-labeled plasmid DNA. The size of nanospheres used is $0.24 \mu \mathrm{m}$ and their crosslinking time is (口) 48 or (घ) $120 \mathrm{hr}$. (A) Time profiles of percent cellular internalization of nanospheres. (B) Time profiles of percent cellular internalization of plasmid DNA incorporated in nanospheres. ${ }^{*}, \mathrm{p}<0.05$; significant between the two groups. 
Table 1. Preparation and characterization of gelatin microspheres and nanospheres.

\begin{tabular}{ccc}
\hline Emulsification method (pore size $\left.{ }^{\mathrm{a}}\right)$ & Solvent & Sphere size $(\mu \mathrm{m})$ \\
\hline stirring & - & $7.80 \pm 2.88$ b) $^{\mathrm{b}}$ \\
filtration $(0.6 \mu \mathrm{m})$ & 2-butanol & $1.86 \pm 0.84$ \\
filtration $(0.2 \mu \mathrm{m})$ & 2-butanol & $0.83 \pm 0.20$ \\
filtration $(0.2 \mu \mathrm{m})$ & 2-butanol / acetone & $0.24 \pm 0.11$ \\
filtration $(0.2 \mu \mathrm{m})$ & acetone \\
\hline
\end{tabular}

a) The pore size of glass filters used for microspheres and nanospheres preparation

b) Mean \pm standard error

c) Cannot be measured

Table 1. Doi et al. 


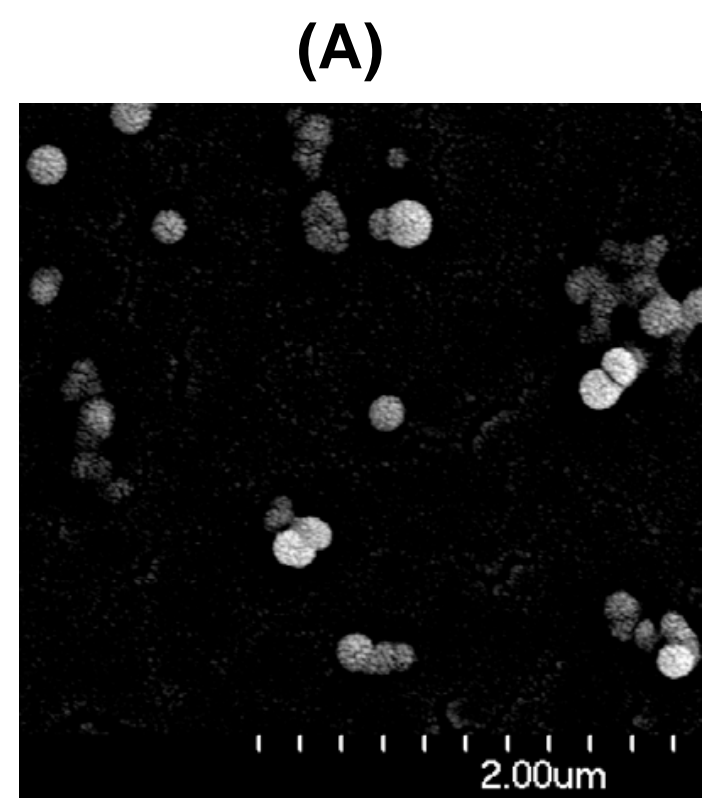

(B)

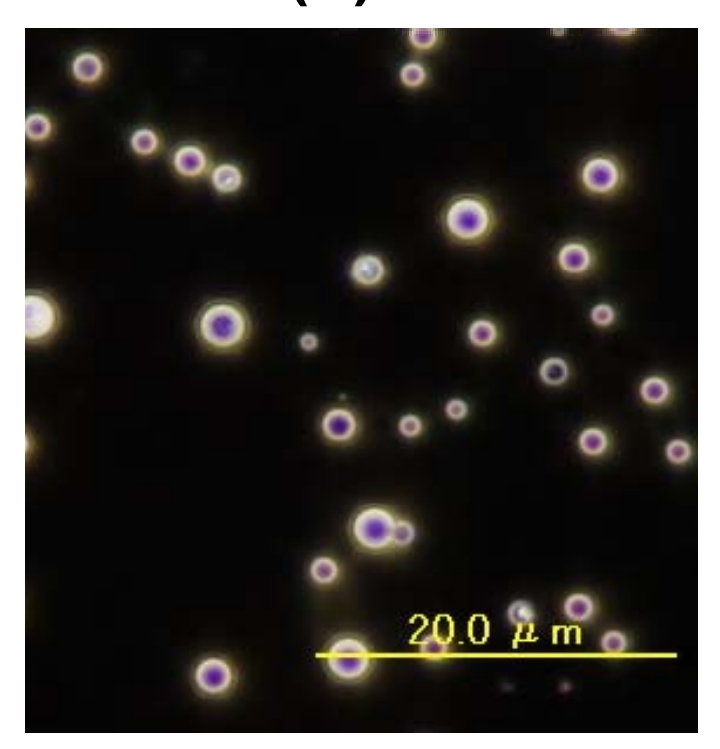

(C)

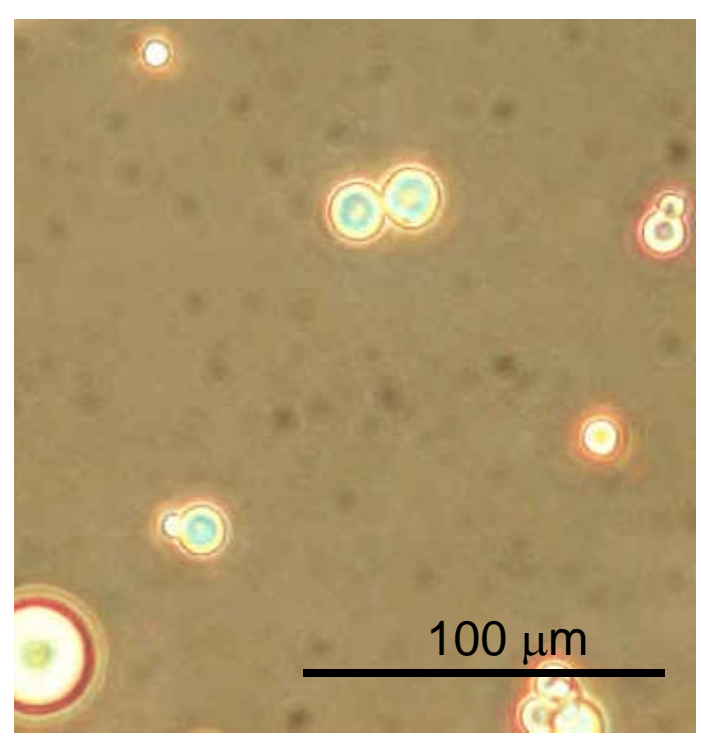

Figure 1. Doi et al. 


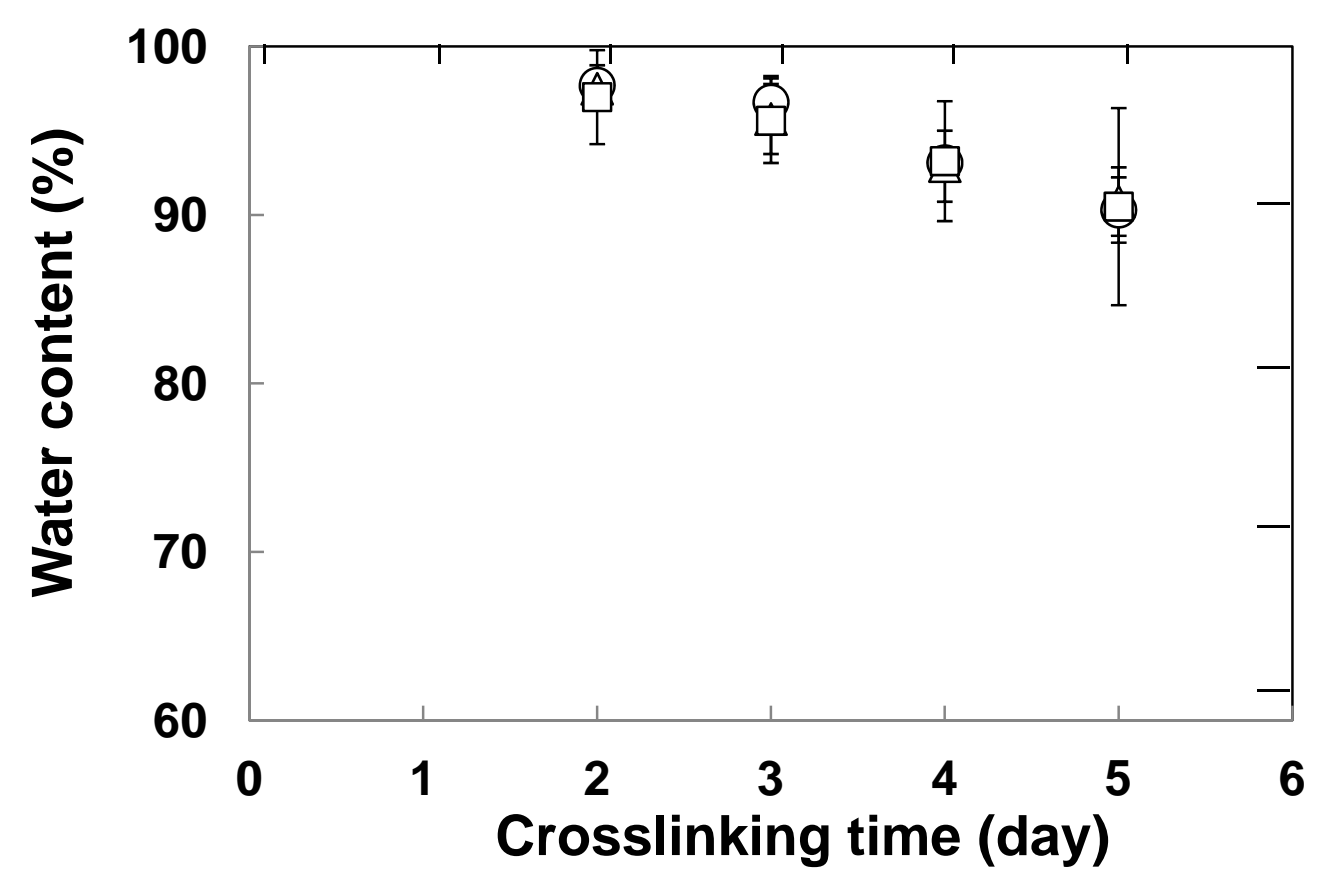

Figure 2. Doi et al. 


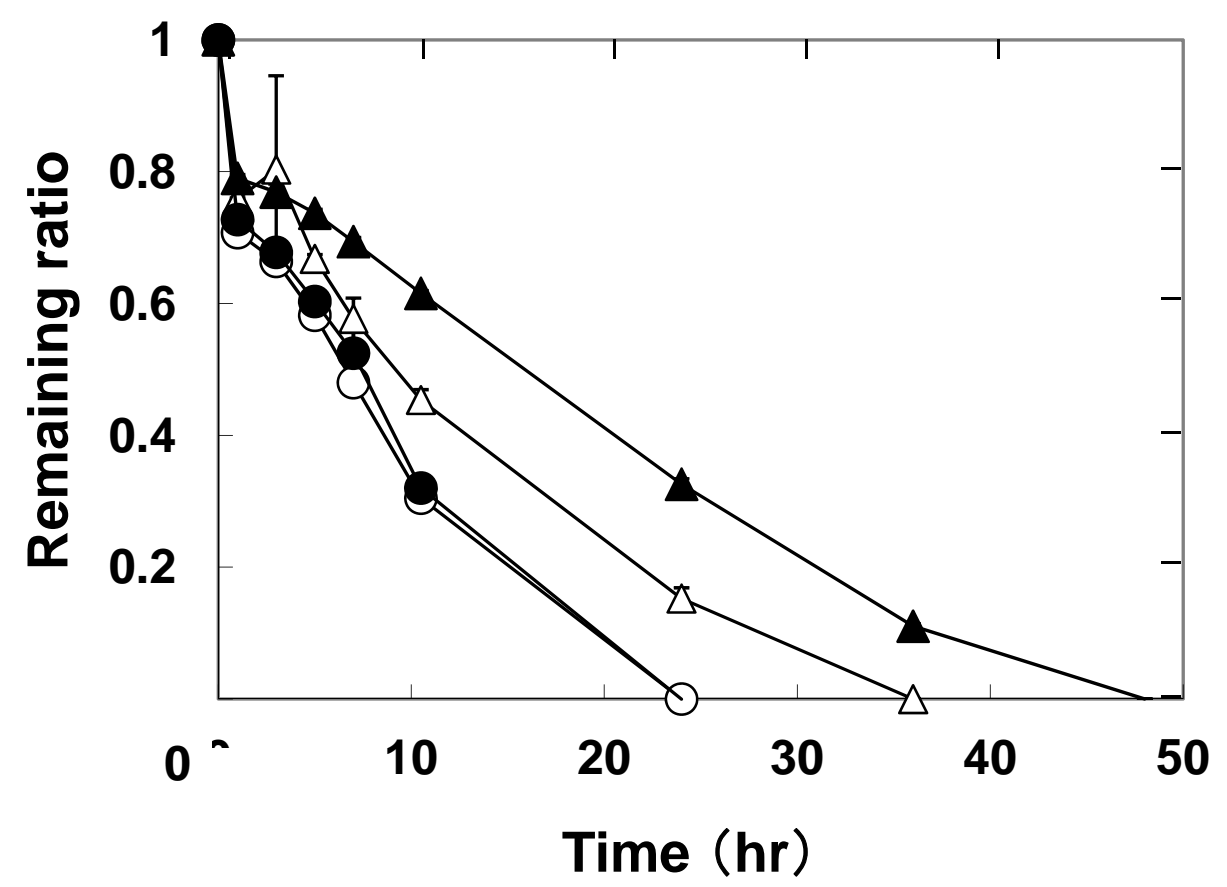

Figure 3. Doi et al. 


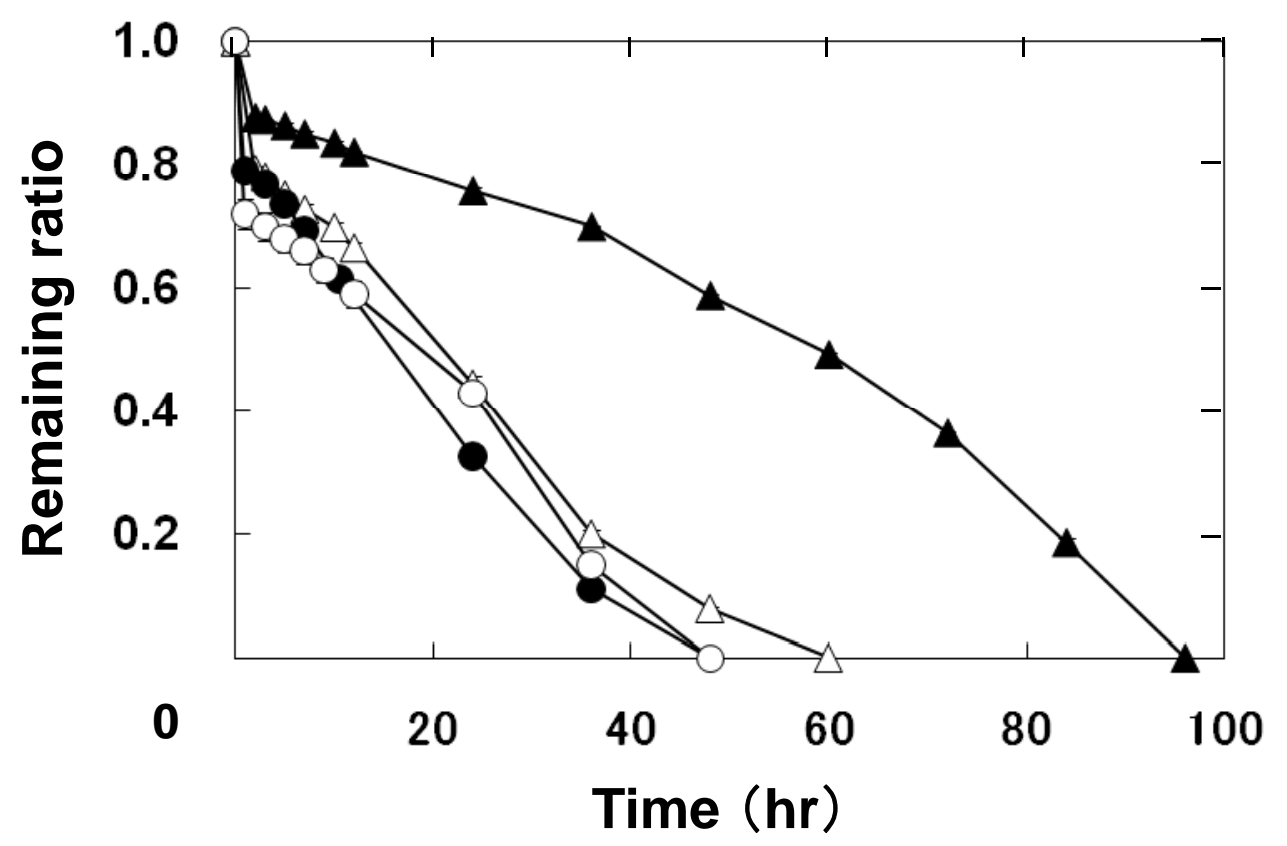

Figure 4. Doi et al. 


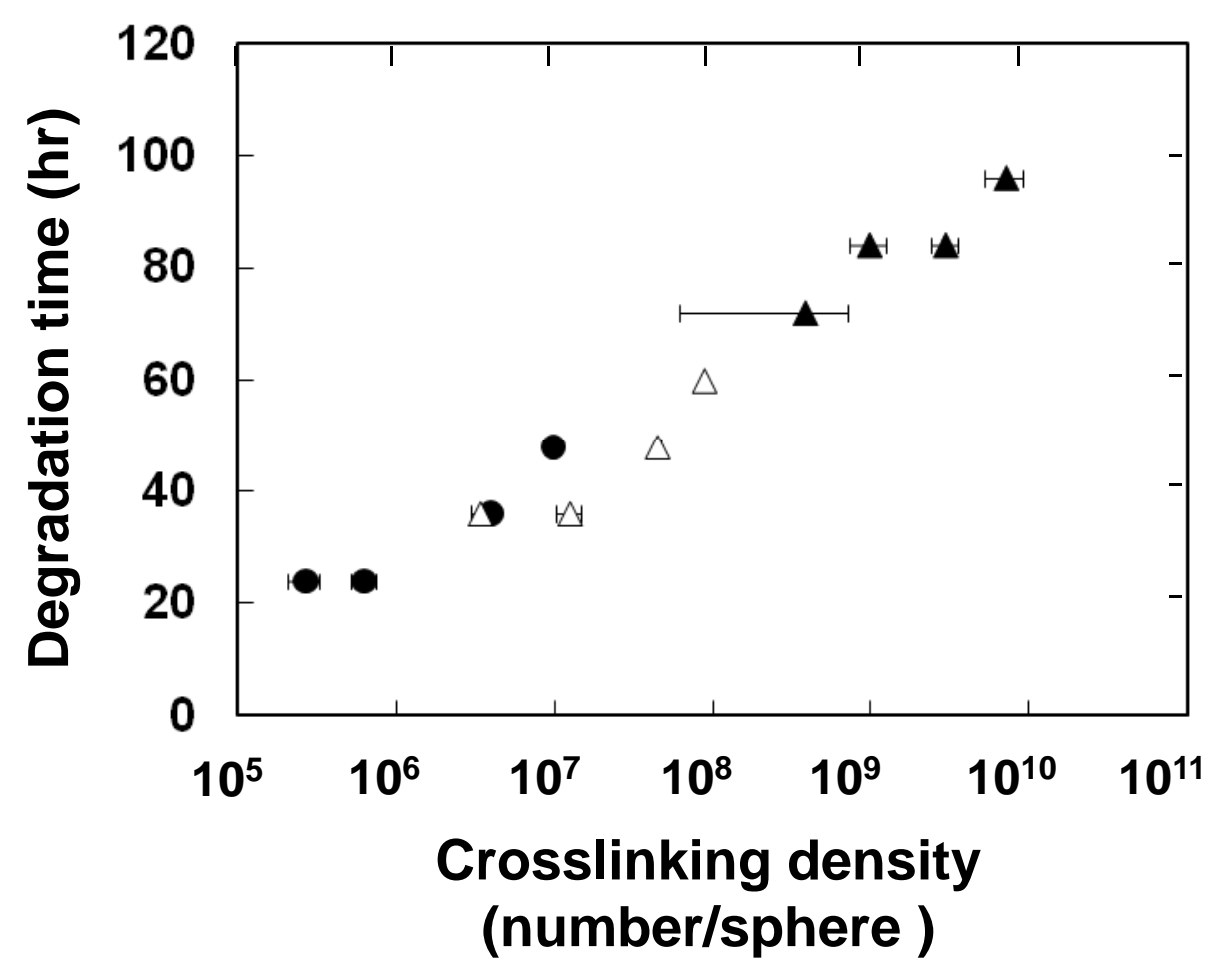

Figure 5. Doi et al. 


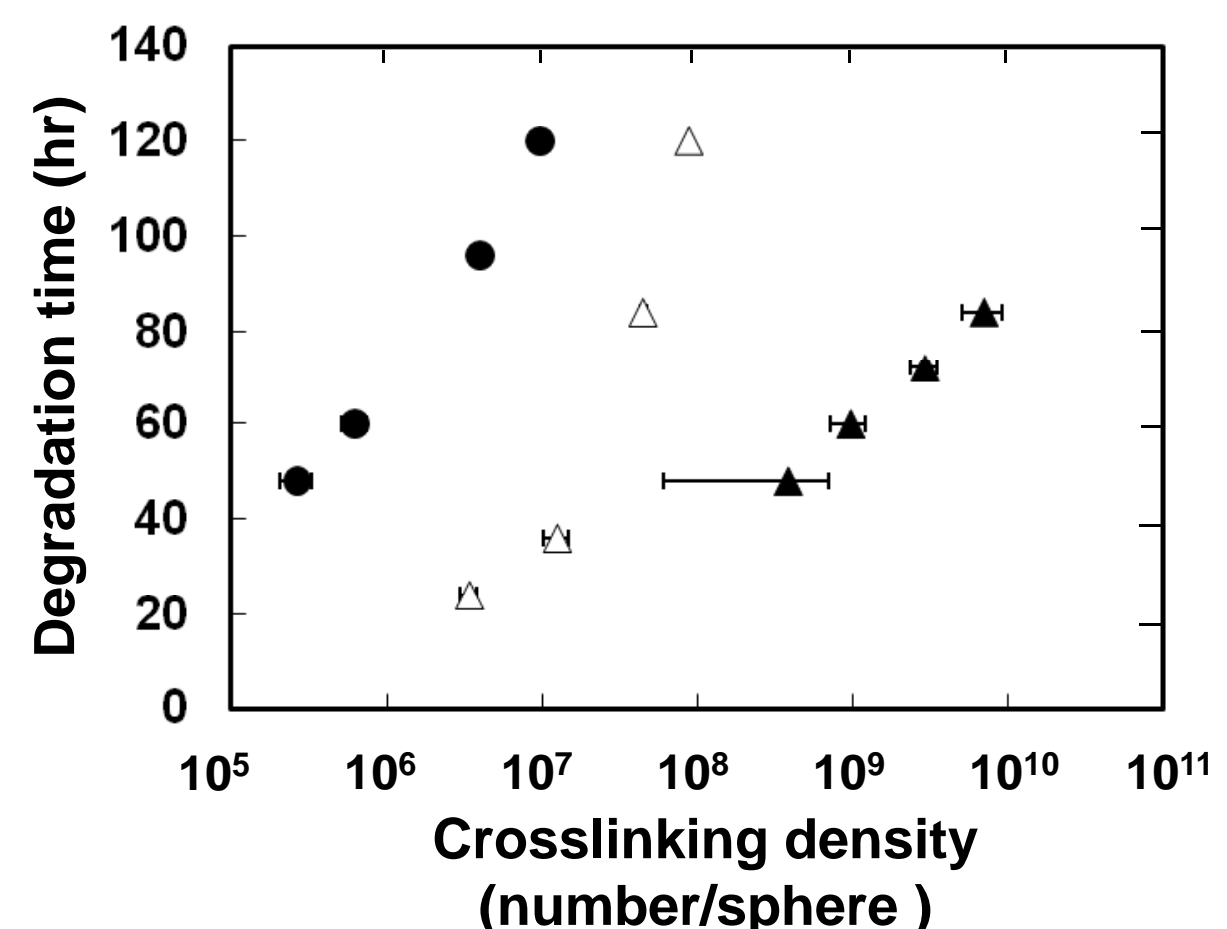

Figure 6. Doi et al. 


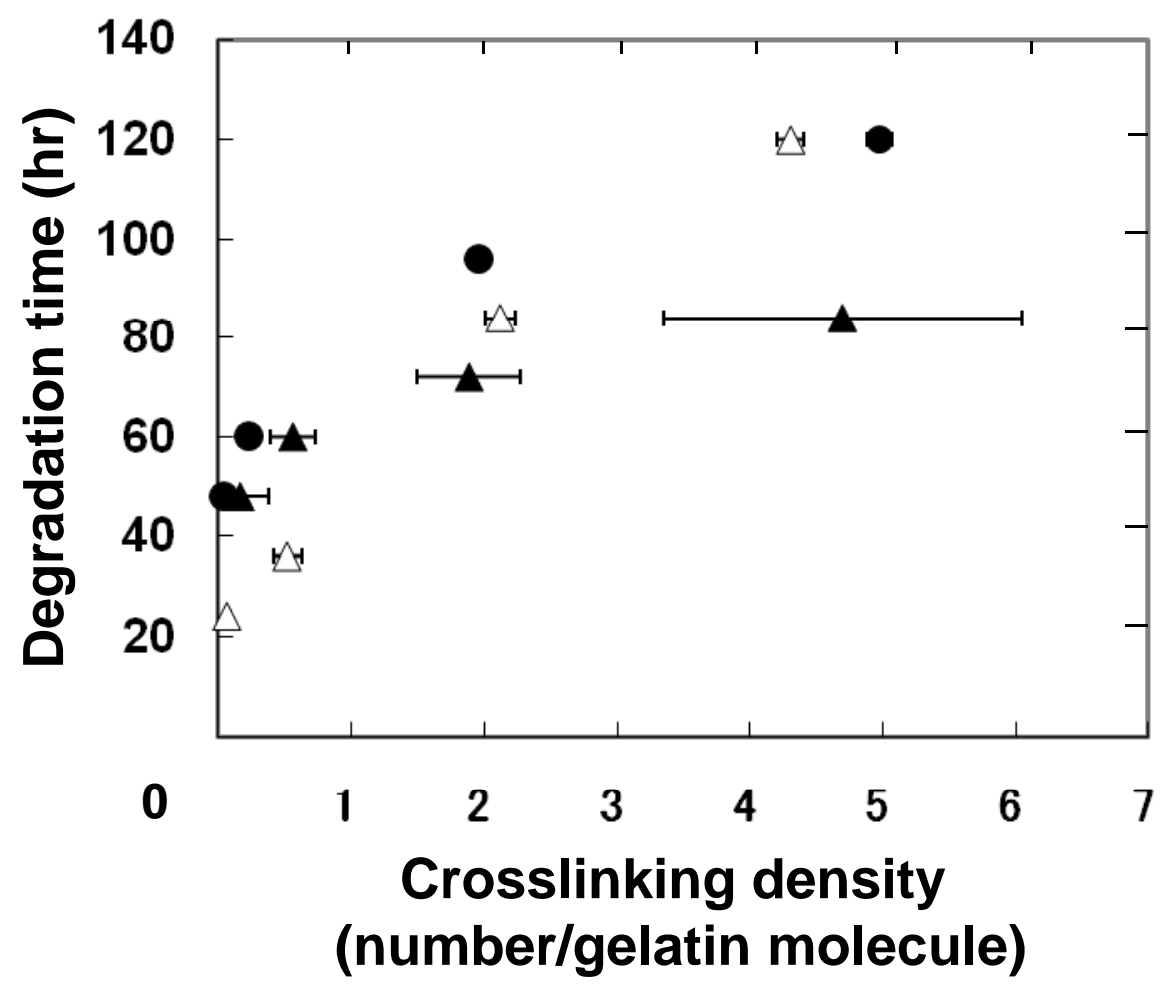

Figure 7. Doi et al. 


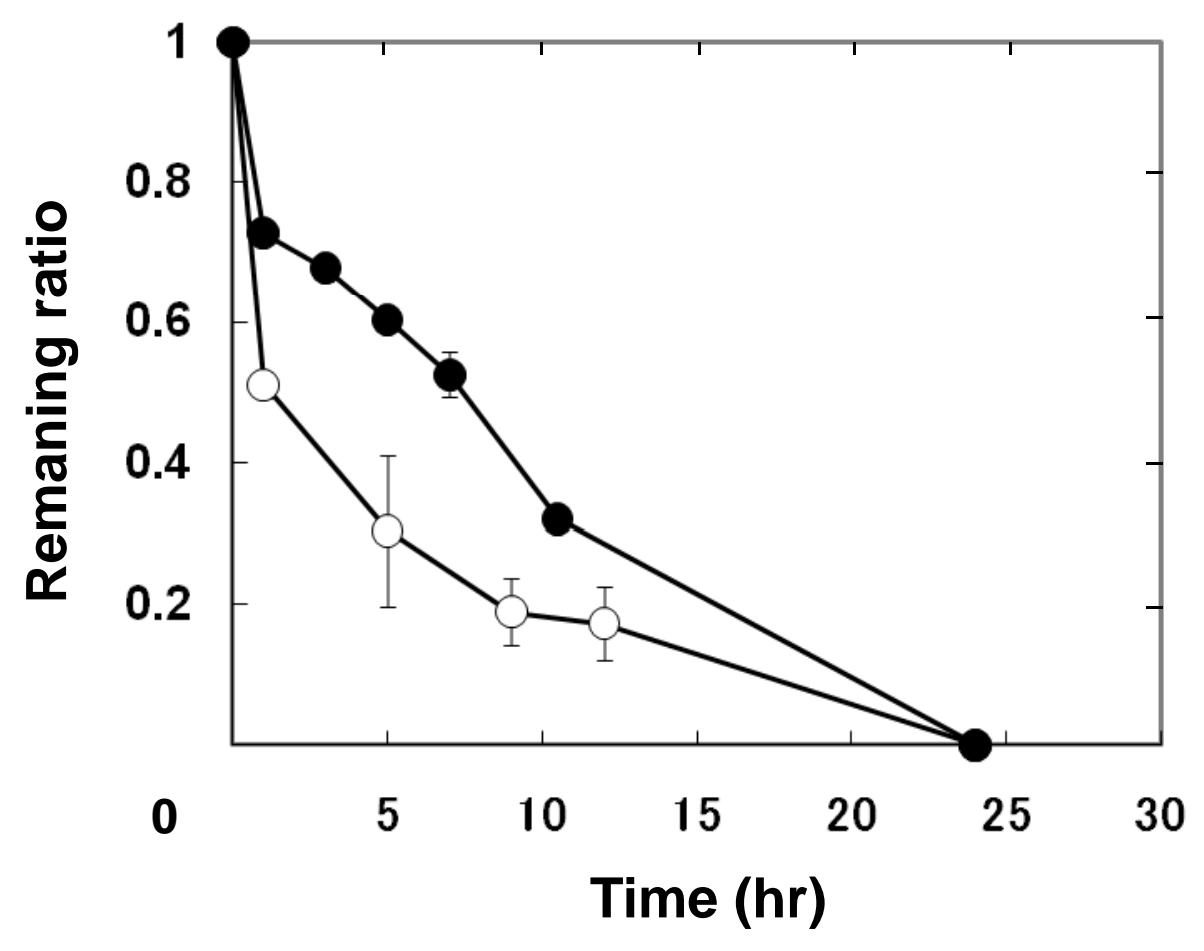

Figure 8. Doi et al. 


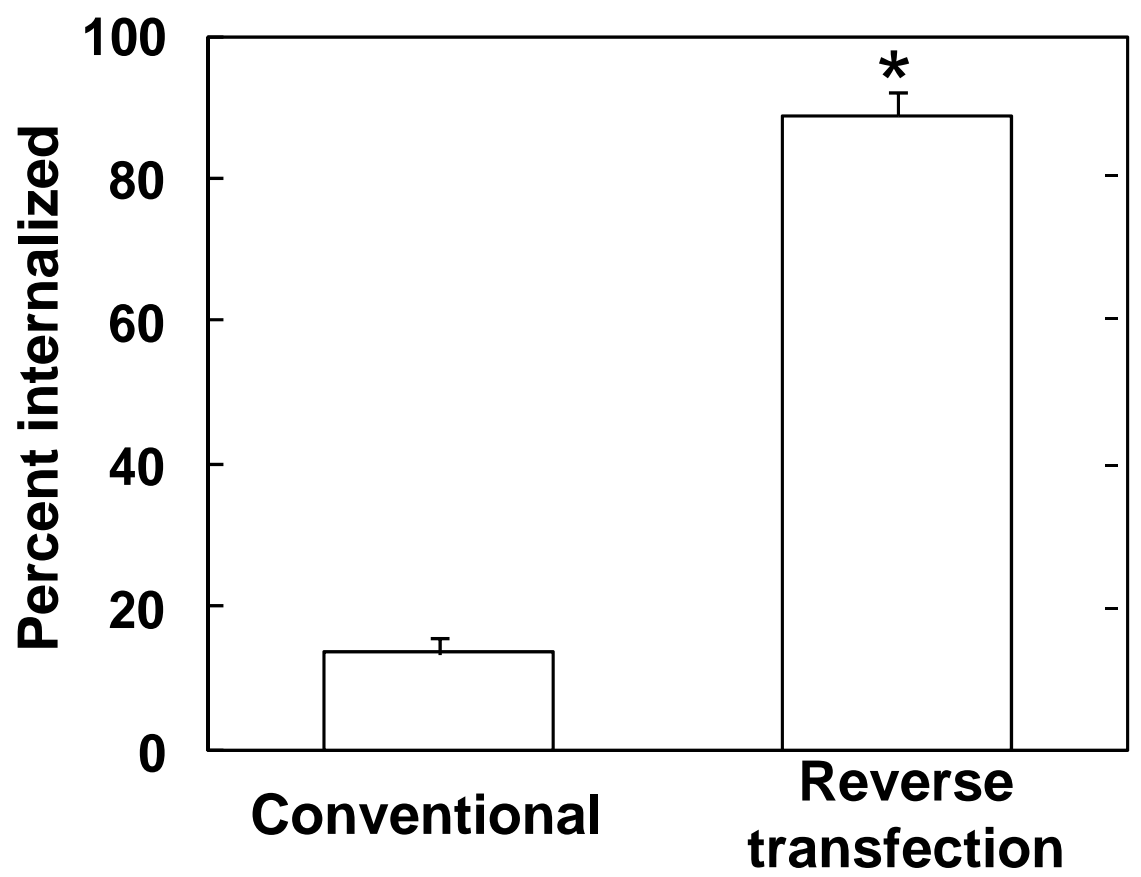

Figure 9. Doi et al. 


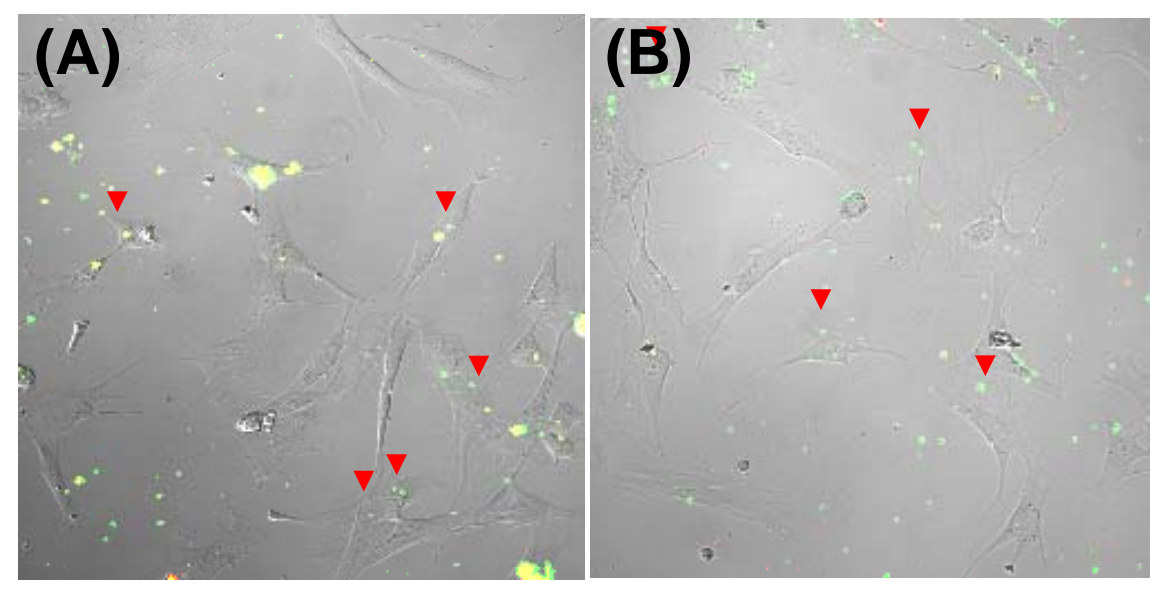

(C)

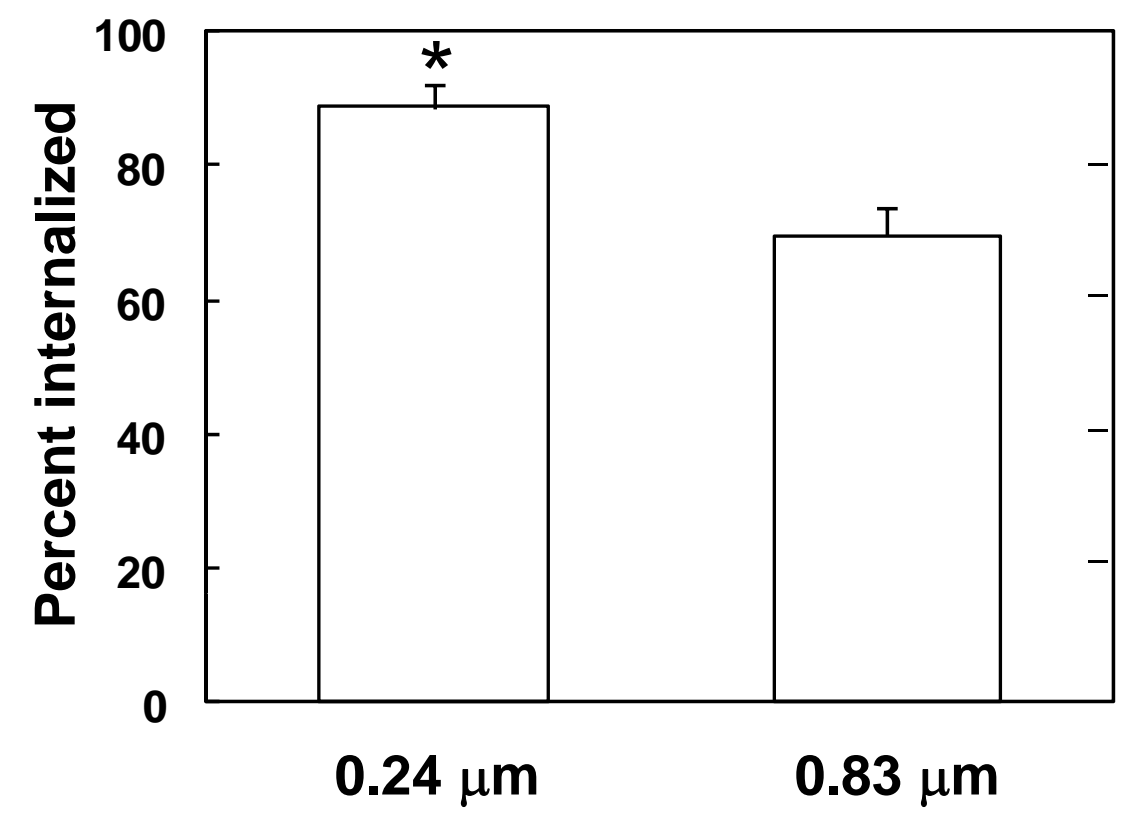

Figure 10. Doi et al. 
(A)

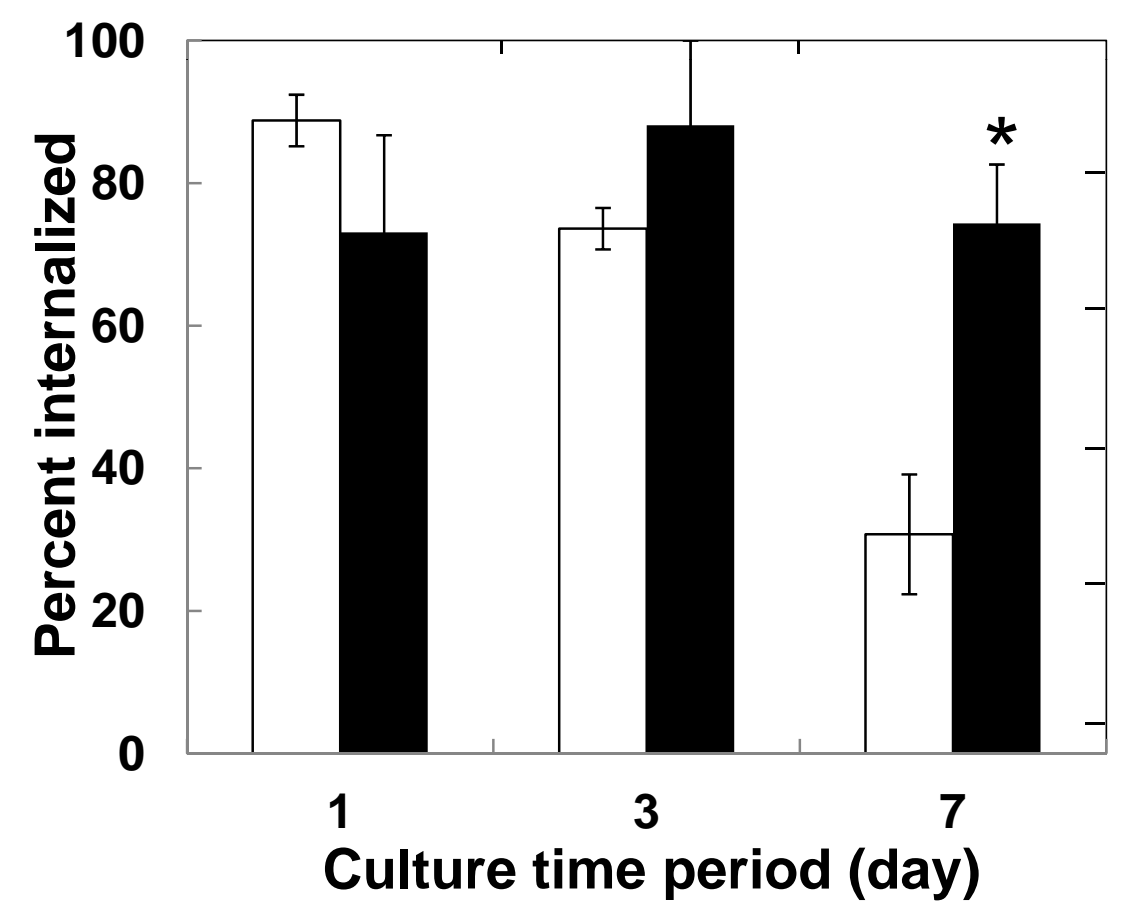

(B)

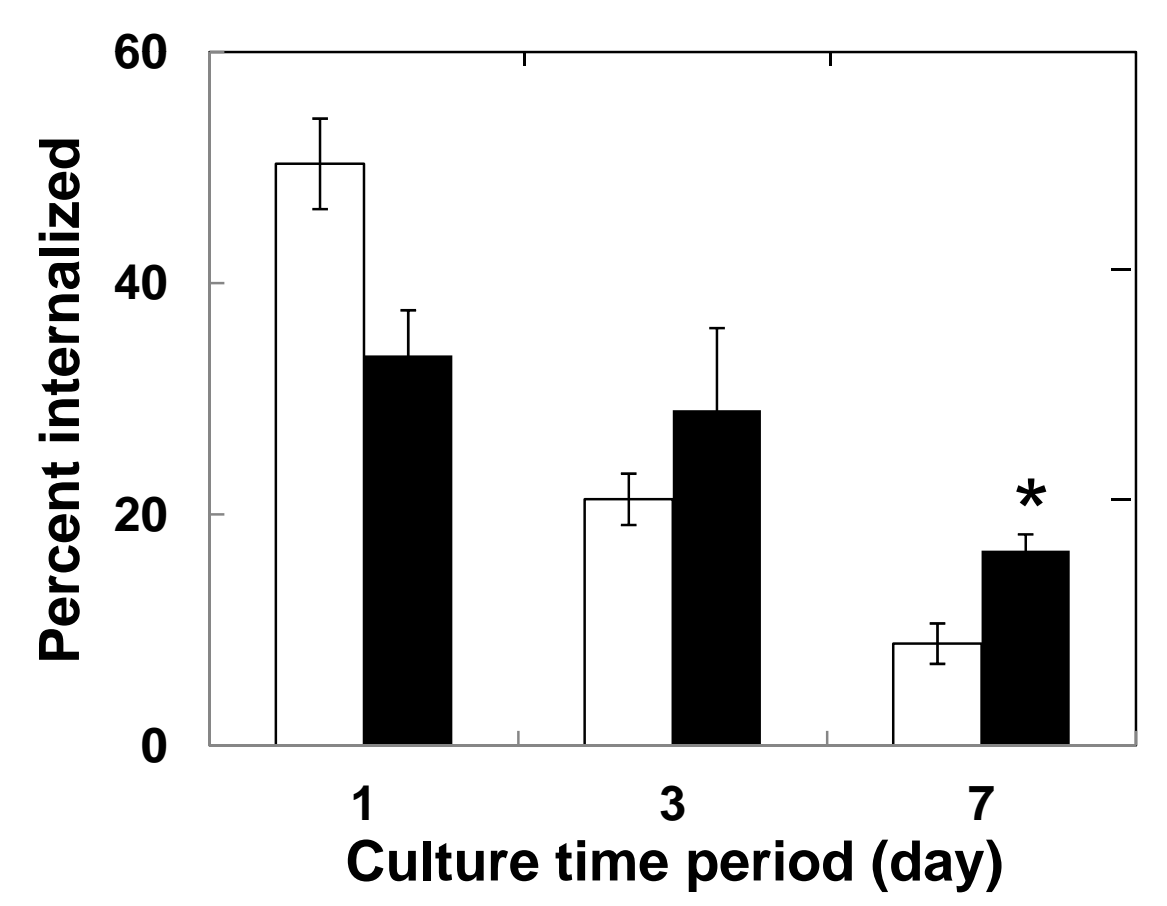

Figure 11. Doi et al. 